\title{
Performance of Dual-Axis Solar Tracker versus Static Solar System by Segmented Clearness Index in Malaysia
}

\author{
Jhee Fhong Lee, ${ }^{1,2}$ Nasrudin Abd. Rahim, ${ }^{1,3}$ and Yusuf A. Al-Turki ${ }^{3}$ \\ ${ }^{1}$ UM Power Energy Dedicated Advanced Centre (UMPEDAC), University of Malaya, 59990 Kuala Lumpur, Malaysia \\ ${ }^{2}$ Faculty of Engineering, University of Malaya, 50603 Kuala Lumpur, Malaysia \\ ${ }^{3}$ King Abdulaziz University, Jeddah 21589, Saudi Arabia
}

Correspondence should be addressed to Jhee Fhong Lee; wallacelee86@gmail.com

Received 17 July 2013; Accepted 21 October 2013

Academic Editor: Mahmoud M. El-Nahass

Copyright (C) 2013 Jhee Fhong Lee et al. This is an open access article distributed under the Creative Commons Attribution License, which permits unrestricted use, distribution, and reproduction in any medium, provided the original work is properly cited.

\begin{abstract}
The performance of Dual-Axis Solar Tracker (DAST) and Static Solar System (SSS) with respect to clearness index in Malaysia is presented. An attempt to investigate the correlation between clearness index with energy gain and efficiency of DAST over SSS is being done experimentally. A good correlation could not be found out from the daily clearness index. It is due to the more profound advantage of DAST in the morning and evening compared to midday as it is able to follow the sun's position. Hence, the daily clearness index is divided into three segments which are morning, midday, and evening to interpret the energy gain and efficiency better. A clearer correlation with low standard deviation can be observed on the segmented clearness index analysis. The energy gain and efficiency of seven cities in Malaysia is being estimated with the segmented clearness index and compared to the result generated from anisotropic radiation model. A similar trend is obtained and it has shown that the segmented clearness index could be utilized as a graphical method for estimation of energy gain and efficiency of DAST over SSS.
\end{abstract}

\section{Introduction}

Solar energy has gained tremendous attention in recent years due to various reasons such as the fluctuating of the price of crude oil, awareness of public on environment issues, supporting policies and subsidies taken by local government to boost renewable energy sectors, and price reduction of photovoltaic (PV) panels. Many large-scale solar farms were commissioned in USA, Europe, and China as the global PV price is dropping rapidly in recent years which agrees with the Swanson's law [1]. However, the PV generated electricity is not competitively enough compared to fossil fuel (oil, gas, and coal) especially in urban areas. Hence, more intensive research and development on PV cell material science are required in order to overleap the conversion efficiency hurdle and reduce the manufacturing cost. Meanwhile, there are several approaches available for increasing the performance of PV system other than exploring on new material for PV cell. For instance, Maximum Power Point Tracking (MPPT) which able to draw maximum power by tracking and operating on the maximum power point of the PV arrays [2], solar tracking that able to maximize the power captured from sun by following the sun path [3], and so forth. Above all, solar tracking poses great advantage to enhance the PV system efficiency as compared to a static solar system [4]. Dual-Axis Solar Tracker (DAST) is a type of solar tracker with two rotational axes which enable it to align the PV panels and point directly towards the solar disk at all times $[3,5]$. Solar irradiance $\left(\mathrm{W} / \mathrm{m}^{2}\right)$ is a measure of amount of sunlight fall on a surface. It is the most crucial factor in determining the performance of a PV panel. The solar energy captured by $\mathrm{PV}$ panels is directly proportional with the solar irradiance received by PV panels. With PV panels facing the sun at all times, it ensures that maximum solar energy being converted into electrical energy during the course of the day. Hence, substantial gain can be obtained by using DAST compared to Static Solar System (SSS).

From the literature, various tracking methods have been proposed and validated around the world in previous works and each of them has its pros and cons in terms of efficiency, 
complexity, and cost. Figure 1 shows the minimum, maximum, and average efficiency of some solar tracking works being reported experimentally and by simulation in other countries [6-18]. Apparently, the difference in solar tracking efficiency that varies greatly among the countries reported due to different geographic location, local landscape, and climate [19]. Moreover, the efficiency of solar tracking in the same region during different seasons also differs significantly. The efficiency normally top in the summer, with a marginal performance in winter and the spring and fall have average efficiency.

Malaysia as a country which lies at $1^{\circ}$ to $7^{\circ}$ north of equator has an equatorial climate and long hours of sunshine throughout the year. There are enormous potential for solar energy to be successful at this land. However, the potential for the DAST is rarely reported and investigated in this region. Hence, a quantitative advantage of DAST over SSS in this country still remains unknown although the consistently long sun hours suggested a promising outcome. Thus, it would be one of the endeavors for this study to carry out an investigation on some of the cities in Malaysia regarding their performance enhancement for installation of DAST over SSS. The advantage on the financial perspective would also be analyzed and a comparison can be made on the suitability for DAST installation on seven cities in Peninsular Malaysia.

While having better efficiency over SSS, the additional costs for the DAST could not be overlooked. The tracking mechanism requires extra mechanical structure and motors to rotate the PV panels according to the sun's position. Operational and maintenance cost of the DAST will also be higher than SSS. Hence, estimation of the efficiency/energy gain of DAST over SSS is essential, and need to be part of the site evaluation criteria. As a rule of thumb, the gain from the DAST over SSS would have to surpass the additional costs whereby the profitability and sustainability of the DAST especially in large scale solar power plant are guaranteed. However, as shown in Figure 1, the reported efficiency improvement can vary from as low as $10 \%$ to as high as $75 \%$. The large variation of DAST efficiency complicates the evaluation process for adopting DAST over SSS. Besides that, performance enhancement of DAST over SSS for an equator region as Malaysia is not being investigated so far.

So far, comparison of efficiency and energy gain of DAST over SSS has been done by physically installing both systems on the site of interest. This method is not only expensive but also time consuming, since data over a sufficiently long period of time is needed to facilitate a meaningful comparison between the two systems. Moreover, the results obtained are not directly applicable onto other sites. Hence, there is a need for a method to estimate the gain of DAST over SSS in a more cost- and time-effective manner such that the site evaluation can be made more straightforward.

Cruz-Peragón et al. quantify the extra solar gain of DAST over SSS with respect to latitude of the cities in Spain based on the Reindl anisotropic model and Liu \& Jordan isotropic model $[20,21]$. Based on his finding, the former method is more useful and better represent the climate of Spain territory as compared to isotropic model. Most of the cities in Spain territory are suitable for DAST while a few cities are not recommended due to various reasons including high latitude, high rainfall, and coastal region.

In this paper, an attempt is made to correlate the performance enhancement of DAST based on the clearness index of the sites in Malaysia. Subsequently, this correlation is used to estimate the performance boost of DAST at seven cities in Malaysia.

\section{Literature Review}

2.1. Clearness Index. Clearness index is chosen as the sole variable in this work as it is derived from solar irradiance, the most fundamental factor that influences the performance of a PV system. Clearness index represents the ratio of the average global solar irradiation $G$ on a horizontal surface to the extraterrestrial solar irradiation $H_{o}$ on the same surface and given by the following Equations for daily and hourly values, respectively [22].

For daily:

$$
K_{T}=\frac{G}{H_{o}} .
$$

For hourly:

$$
k_{T}=\frac{I_{G}}{I_{o}}
$$

The data of global solar radiation over a day and over an hour, $I_{G}$, are available from measurements of total solar radiation on a horizontal surface by using a pyranometer. The hourly clearness index function could be utilized to calculate clearness index for longer period by replacing the global solar radiation and extraterrestrial radiation for the desired period into (2). Meanwhile, the extraterrestrial solar radiations $H_{o}$ and $I_{o}$ can be defined as the solar radiations incident on a horizontal plane outside the atmosphere over a day and a designated period of time within a day, respectively. In other words, this is the sunlight reaching the ground of the earth without the presence of atmosphere. The amount of extraterrestrial radiation reaching the earth ground relies on the relative position of the earth to the sun on its elliptical orbit around the sun and the earth declination through this orbit. $H_{o}$ and $I_{o}$ can be calculated by using (3) as follows:

$$
\begin{aligned}
& H_{o}= \frac{24 \times 3600}{\pi} G_{\mathrm{SC}}\left[1+0.033 \cos \left(\frac{360 n}{365}\right)\right] \\
& \times\left(\cos \phi \cos \delta \sin \omega_{s}+\frac{\pi \omega_{s}}{180} \sin \phi \sin \delta\right), \\
& I_{o}= \frac{12 \times 3600}{\pi} G_{\mathrm{SC}}\left[1+0.033 \cos \left(\frac{360 n}{365}\right)\right] \\
& \times {\left[\cos \phi \cos \delta\left(\sin \omega_{2}-\sin \omega_{1}\right)\right.} \\
&\left.\quad+\frac{\pi\left(\omega_{2}-\omega_{1}\right)}{180} \sin \phi \sin \delta\right] .
\end{aligned}
$$




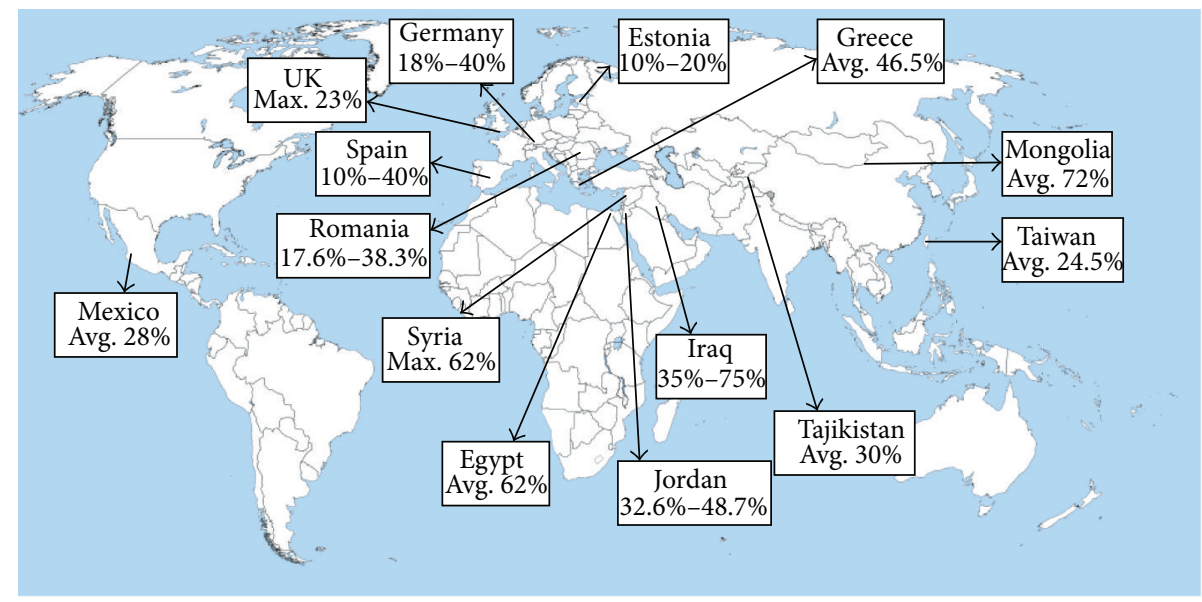

FIGURE 1: Efficiency of solar tracker works reported around the world.

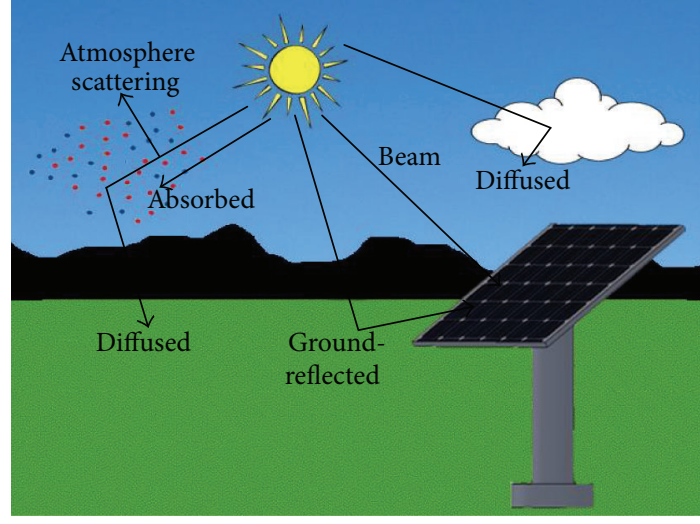

FIGURE 2: The three components of global solar radiation.

The parameters in the equations can be found in the nomenclature.

$H_{o}$ from the sun passes through and is attenuated by the atmosphere before reaching the surface on the earth as $G$. Global solar irradiation consists of direct/beam radiation, diffuse radiation, and reflected radiation. Beam radiation is coming directly from the solar disk on a clear sky without being obstructed by the clouds while diffuse radiation is the radiation found in cloudy day with the direct solar ray being firstly scattered by molecules and particles on the clouds before reaching the solar panels. There is also a very meager amount of radiation reflected from the clouds and ground surface, namely, reflected radiation. The components of global solar radiation are illustrated in Figure 2.

The clearness index is higher in a sunny day as the solar radiation is dominated by beam radiation and less energy loss through diffusion and reflection. A higher clearness index will lead to a higher energy generated and efficiency for DAST. Hence, the relationship of clearness index with energy gain and efficiency of DAST is quantified and investigated experimentally. With the knowledge of the correlation, it is able to offer an alternative guideline for evaluating the performance enhancement of DAST to a specific site.

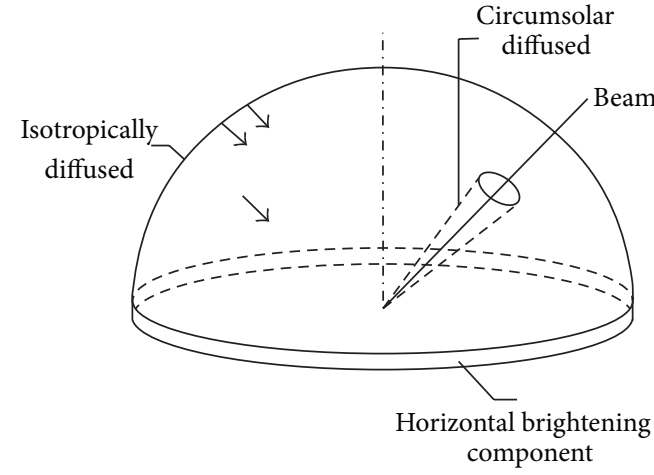

FIGURE 3: Circumsolar and horizon brightening components added to the isotropic component in diffusion model [24].

2.2. Diffuse Radiation Model. Diffuse radiation model is useful for evaluating the global irradiation over tilted surface by using the global solar radiation over horizontal surface. Liu and Jordan isotropic model [23] is widely used as it is the simplest diffusion model for obtaining the global irradiation over tilted surface. It assumes a uniform distribution of the ground-reflected radiation and sky-diffuse radiation on the celestial hemisphere. However, its simplistic nature has lead to some weaknesses. It neglected the contribution of circumsolar diffuse radiation and horizontal brightening to the total diffused radiation. These two components contribute a remarkable portion in the clear days. Circumsolar diffused radiation resulted from forward scattering of beam radiation and was mainly concentrated in the part of the sky around the solar disk.

Meanwhile, the horizon brightening component is concentrated near the horizon and is most profound in clear skies [24]. These additional components are schematically shown in Figure 3. Isotropic model tends to underestimate the amount of diffuse radiation in clear skies, which leads it into poorer response in clear days. Thus, the whole estimated irradiation can fall below the actual value from $3 \%$ to $9 \%$ $[23,24]$. 
In order to have better estimation on the diffuse radiation, anisotropic models has to be adopted as larger diffuse components such as circumsolar diffuse radiation and horizontal brightening are taken into account. By analyzing various methodologies of anisotropic models, HDKR anisotropic model (Hay, Davies, Klucher, Reindl model) [21] is found to be fairly suitable as some correction factors are added to account for the horizon brightening on clear days as well as cloudiness.

Anisotropic model considers that the radiation on the tilted surface is contributed by three components which are beam, anisotropic diffuse, and solar radiation diffusely reflected form the ground as in

$$
\begin{aligned}
I_{T}= & \left(I_{B}+I_{D} A_{i}\right) R_{B}+I_{D}\left(1-A_{i}\right)\left(\frac{1+\cos \beta}{2}\right) \\
& \times\left(1+f \sin ^{3}\left(\frac{\beta}{2}\right)\right)+I_{G} \rho\left(\frac{1-\cos \beta}{2}\right) .
\end{aligned}
$$

Erbs et al. correlation [25] in (5a), (5b), and (5c) makes it possible to obtain the isotropic diffuse component of radiation $I_{D}$, by using the clearness index $k_{t}$ at each time while the beam radiation is then being found from the difference between global solar radiation over horizontal surface $I_{G}$ and $I_{D}$ as in (6). Consider

$$
\begin{gathered}
\frac{I_{D}}{I_{G}}=1.0-0.09 k_{t}, \quad \text { for } k_{t} \leq 0.22, \\
\frac{I_{D}}{I_{G}}=0.9511-0.1604 k_{t}+4.488 k_{t}^{2}-16.638 k_{t}^{3} \\
+12.336 k_{t}^{4} \quad \text { for } 0.22<k_{t} \leq 0.8 \\
\frac{I_{D}}{I_{G}}=0.165 \text { for } k_{t}>0.8, \\
I_{G}=I_{D}+I_{B} .
\end{gathered}
$$

Geometric factor $R_{B}$ is the ratio of beam radiation on tilted surface to that on a horizontal surface at any time [22] that can be obtained from (7). Anisotropy index $A_{i}$ is a function of the transmittance of the atmosphere for beam radiation. A modulating factor $f$ is added into HDKR diffusion model by Klucher to account for cloudiness of the sky as follows:

$$
\begin{gathered}
R_{B}=\frac{\cos \theta}{\cos \theta_{z}}, \\
A_{i}=\frac{I_{B}}{I_{o}}, \\
f=\sqrt{\frac{I_{B}}{I_{G}}} .
\end{gathered}
$$

Equation (10) is the angle of incidence of the solar beam radiation on a tilted surface which is one of the important expressions to construct the anisotropic diffuse radiation model. The solar radiation obtained from this model is compared to the experimental result of the proposed DAST prototype. The DAST prototype is using equatorial tracking system. Photoresistors are used as the sensors to track the position of the sun. Hence, angle of incidence of the solar beam which is one of the elements of mathematical approach is not adopted for the solar tracking purpose of the proposed DAST prototype.

$\theta_{z}$ is the angle of incidence of beam radiation on tilted surface and solar zenith angle. Consider

$$
\begin{aligned}
\cos \theta= & \sin \delta \sin \phi \cos \beta-\sin \delta \cos \phi \sin \beta \cos \gamma \\
& +\cos \delta \cos \phi \cos \beta \cos \omega \\
& +\cos \delta \sin \phi \sin \beta \cos \gamma \cos \omega \\
& +\cos \delta \sin \beta \sin \gamma \sin \omega \\
& \cos \theta_{z}=\cos \phi \cos \delta \cos \omega+\sin \phi \sin \delta
\end{aligned}
$$

In addition, the albedo $\rho$ (dimensionless) is the composite ground reflectance which is required to estimate the reflected irradiance. It normally takes a value of 0.2 except for the case of snowy ground it would have a higher value. $\beta$ is the slope of the tilted surface and together with solar azimuth angle $\gamma$ would make sure that the PV system face the sun's position at all times. The location latitude $\phi$, declination $\delta$, and Julian day $n$ are some additional variables to be considered in this model:

$$
\begin{gathered}
\gamma=\operatorname{sign}(\omega)\left|\cos ^{-1} \frac{\cos \theta_{z} \sin \phi-\sin \delta}{\sin \theta_{z} \cos \phi}\right|, \\
\delta=23.45 \sin \left(360 \frac{284+n}{365}\right) .
\end{gathered}
$$

\section{Experimental Setup}

A Dual-Axis Solar Tracker (DAST) and a Static Solar System (SSS) with horizontal orientation are used in this experiment. The solar tracker has two axis of rotation which enable it to rotate along the eastwest and northsouth axis. The type of Dual-Axis Tracking System that is used in this research falls into the category of equatorial as categorized by Alexandru [26]. The DAST proposed here is able to track the sun on two independent axes. The hardware prototype of the DAST and its rotational axes are shown in Figure 4. The daily motion of the sun (from east at dawn to the west at dusk) is tracked by the DAST on first axis (axis "1": daily motion, E: East, $\mathrm{W}$ : West). The rotational range of this axis is $\pm 70^{\circ}$ with the position of solar noon as the reference position $\left(0^{\circ}\right)$. On the other hand, the seasonal variation of the Sun position is tracked by the DAST via the second axis (axis " 2 ": elevation, $\mathrm{N}$ : North, S: South). This axis has $\pm 30^{\circ}$ rotational range for tracking the altitude angle of sun during the different seasons. The reference ("zero") positions for the angular fields of the two rotational axes is better illustrated by referring to Figure 5. Figure 5(a) shows the DAST on a horizontal position at which both daily (eastwest) axis and elevation 
(northsouth) axis on their reference ("zero") position. The normal of the PV panel is coincided with the zenith axis at this position and acts as the reference position of the rotational ranges. The individual reference positions and rotational range of both axes are shown in Figures 5(b) and 5(c), respectively. The sun-tracking mechanism is based on two pairs of Photoresistors as sensors to locate the position of the sun. Two direct-current (DC) linear actuators rotate the PV panel towards the sun's position upon the signals from microcontroller. The tracking is done on a fifteen-minutebasis as the sun moves at a slow speed along the sun path. The control technique adopted in the proposed DAST is a closedloop (with photosensor) approach. The DAST would track the sun's position based on the light intensity received by the photo-sensor. As the movement of the sun is slow in nature, continuous tracking of the sun's position is not necessary. Hence, DAST tracks the sun once in every fifteen minutes. In other words, the fifteen minutes is an interval between consecutive tracking. This main purpose of this approach is to reduce the power consumption for doing redundant tracking. A Sanyo 210 Watt Monocrystalline PV panel is used in the DAST and static system, respectively. The technical characteristics of the PV panel are shown in Table 5. In order to make sure the PV panels on both systems are operating on the Maximum Power Point (MPP), Constant Voltage (CV) Maximum Power Point Tracker (MPPT) with buck converter is connected to PV panels [27]. The open-circuit voltage $\left(V_{\text {oc }}\right)$, short-circuit current $\left(I_{\mathrm{sc}}\right)$, maximum-power voltage, $\left(V_{\mathrm{mp}}\right)$ and maximum-power current $\left(I_{\mathrm{mp}}\right)$ are measured and logged with an interval of 1 minute. The maximum power can be obtained via the product $V_{\mathrm{mp}}$ and $I_{\mathrm{mp}}$. The energy generated in a day or an hour could be obtained by integrating the maximum power along the period of time. The energy gain $\Delta E(\mathrm{kWhr})$ and efficiency $\eta(\%)$ of DAST over SSS which will be widely used in this work can be calculated from energy generated by DAST $E_{\mathrm{DAST}}$ and energy generated by SSS $E_{\mathrm{SSS}}$ and the energy consumption for performing the tracking $E_{C}$ as follows:

$$
\begin{gathered}
\Delta E=E_{\mathrm{DAST}}-E_{\mathrm{SSS}}-E_{\mathrm{C}}, \\
\eta=\frac{\Delta E}{E_{\mathrm{SSS}}} \times 100 \%, \\
E_{C}=\frac{V_{\text {track }}(V) \times I_{\text {drawn }} \times(A) \times \text { time }(\mathrm{hr})}{\text { Area of Panel }\left(\mathrm{m}^{2}\right)} .
\end{gathered}
$$

Indeed, the energy consumption is an essential part in calculating the energy gain $(\Delta E)$. If the energy consumed in tracking is substantial, it might not be worthwhile for adopting a solar tracker. The energy gained from the benefit of tracking could not justify the energy consumed in doing the tracking. The Global Solar Irradiance of both systems is measured by using a well-calibrated Li-Cor (LI 210SA) pyranometer, respectively. The daily data collection starts from $7 \mathrm{am}$ until $7 \mathrm{pm}$ corresponding to the typical day time in Kuala Lumpur, Malaysia, where the experimental setup is installed. The data are logged into EEPROMs and extracted out at the end of the day for analysis in Microsoft Excel and Matlab.

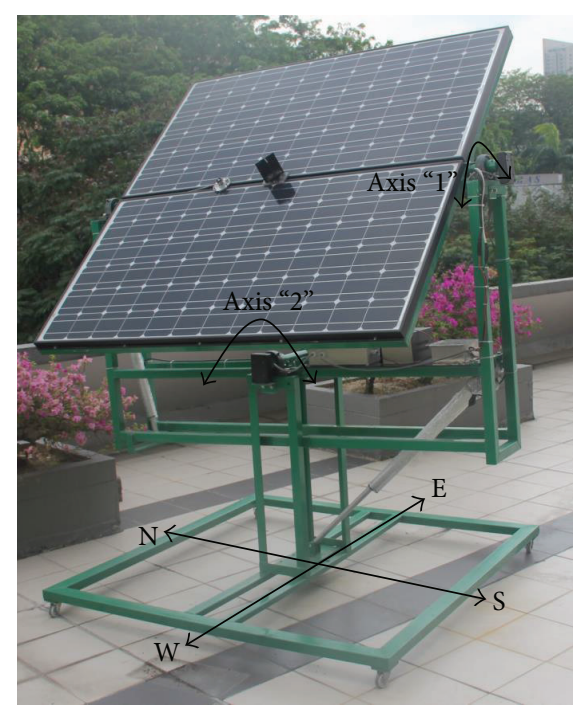

FIGURE 4: The hardware prototype of the DAST and its rotational axes.

\section{Result}

4.1. Results of Daily Power Generation. The maximum power obtained by DAST in a low clearness index day and high clearness index day has substantial difference. Figures 6 and 7 show an example of electrical power generation along a day for an overcast day with $K_{T}$ of 0.34 and a sunny day with $K_{T}$ of 0.62 . In a day with low $K_{T}$, the sun ray is blocked by the clouds which leads to no beam radiation falling on the solar panels. This is clearly indicated on the morning session ( $7 \mathrm{am}$ to $9 \mathrm{am}$ ) and evening session ( $3 \mathrm{pm}$ to $7 \mathrm{pm}$ ) on Figure 8. The diffused radiation is dominant in these two periods and there is no advantage for DAST over the SSS. Kelly and Gibson $[28,29]$ have shown that diffuse radiation is isotropically distributed over the whole sky in an overcast day. Hence, a PV panel positioned horizontally will receive maximum amount of isotropically distributed sky radiation compared to tilted position. Conversely, in a day with high $K_{T}$, the beam radiation is playing a dominant role. $90 \%$ of the global solar radiation is made up by beam radiation [20]. DAST follows the position of the solar disk and ensures that maximum amount of beam radiation strikes the PV panels throughout the day. Figure 8 shows the difference of instantaneous power of DAST and SSS along the sunny day and cloudy day. Tremendous gain is obtained during the morning and evening sessions, while the gain at Table 1 shows the efficiency $(\eta)$ and energy gained by the DAST over SSS in two days with different value of clearness index. The efficiency of DAST over SSS varies from $24.91 \%$ at an overcast day to $82.12 \%$ at a clear day. Likewise, the electrical energy generated also increases drastically from $108 \mathrm{Whr} / \mathrm{m}^{2}$ at a cloudy day to $603 \mathrm{Whr} / \mathrm{m}^{2}$ at a clear day. Apparently, the efficiency of DAST over SSS and additional electrical energy generated in a day are influenced by the clearness index.

Figure 9 presented an example for a day with the measured instantaneous irradiance of DAST and horizontallypositioned SSS together with the modeled irradiance of 


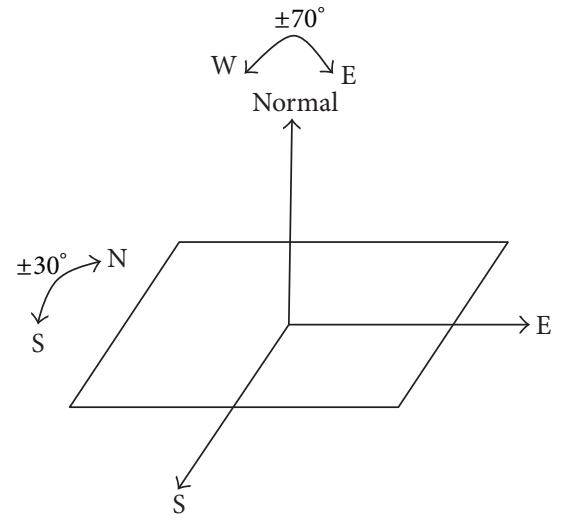

(a)

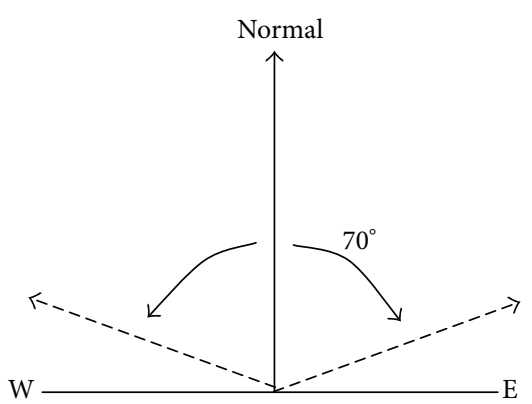

(b)

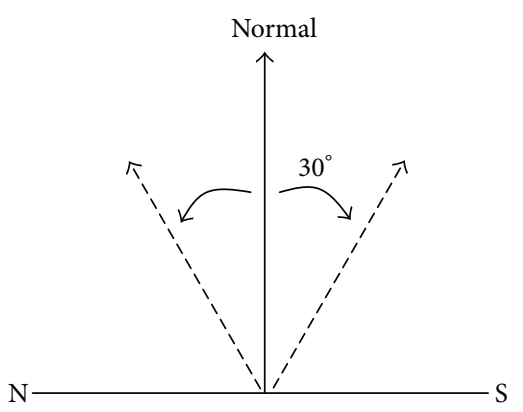

(c)

FIGURE 5: The reference ("zero") positions for the angular fields of the two rotational axes.

TABLE 1: The efficiency $(\eta)$, energy gained by the DAST over SSS, and energy consumption under different clearness index.

\begin{tabular}{lccc}
\hline $\begin{array}{l}\text { Clearness } \\
\text { index, } K_{T}\end{array}$ & $\begin{array}{c}\text { Efficiency, } \eta \\
(\%)\end{array}$ & $\begin{array}{c}\text { Energy generated, } \\
\left(\mathrm{Whr} / \mathrm{m}^{2}\right)\end{array}$ & $\begin{array}{c}\text { Energy } \\
\text { consumption, } \\
\left(\mathrm{Whr} / \mathrm{m}^{2}\right)\end{array}$ \\
\hline 0.34 & 24.91 & 108 & 0.30 \\
0.62 & 82.12 & 603 & 0.30 \\
\hline
\end{tabular}

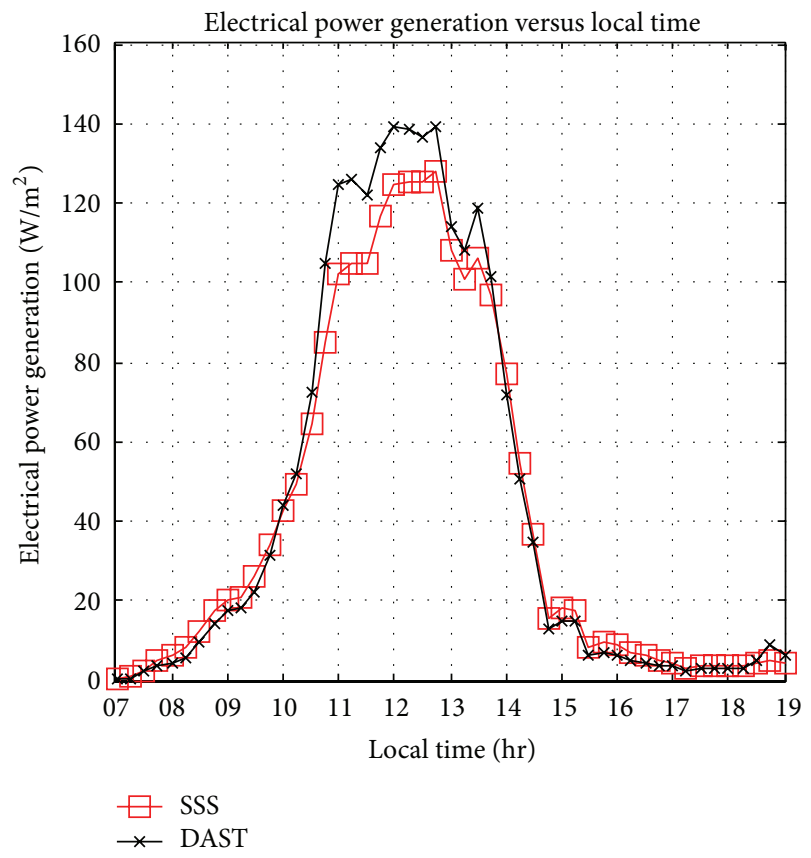

FIGURE 6: Electrical power generation in an overcast day.

DAST. The modeled irradiance of DAST is generated from the global irradiance of horizontally positioned SSS.

There are two noticeable findings that can be interpreted from it. The first finding is that the anisotropic has demonstrated an inspiring result for estimating the irradiance of the

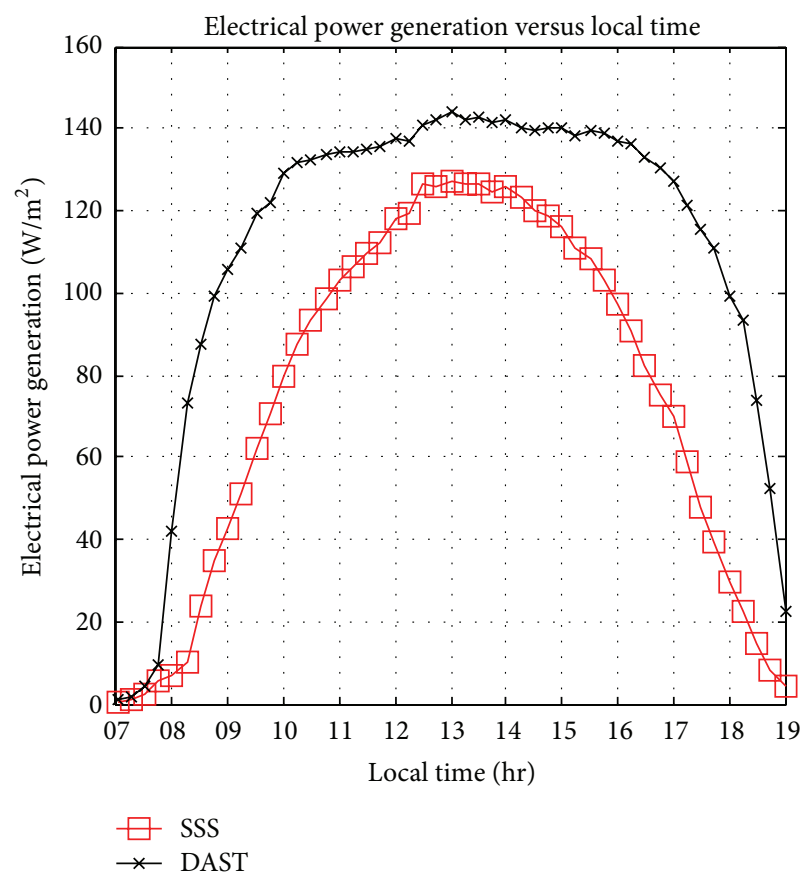

FIgURE 7: Electrical power generation in a sunny day.

DAST as both measured and modeled irradiance have very similar value. The experimental and modeled DAST would track the sun on a similar path in order to have the similar result shown. Hence, HDKR anisotropic diffused model can be reliably used to infer the instantaneous irradiances of DAST. The second finding is that the irradiances captured by both DAST and SSS are not far off from each other during the midday. It means the incidence angle of sun ray falling on both does not differ much at this period compared to other periods of the day. It agrees with the result from Figure 8 that the advantage of DAST lies on morning and evening session.

For the proposed DAST, the energy consumed is marginal compared to the additional energy gain from tracking. Thus, the energy consumption $\left(E_{C}\right)$ is not included in the 


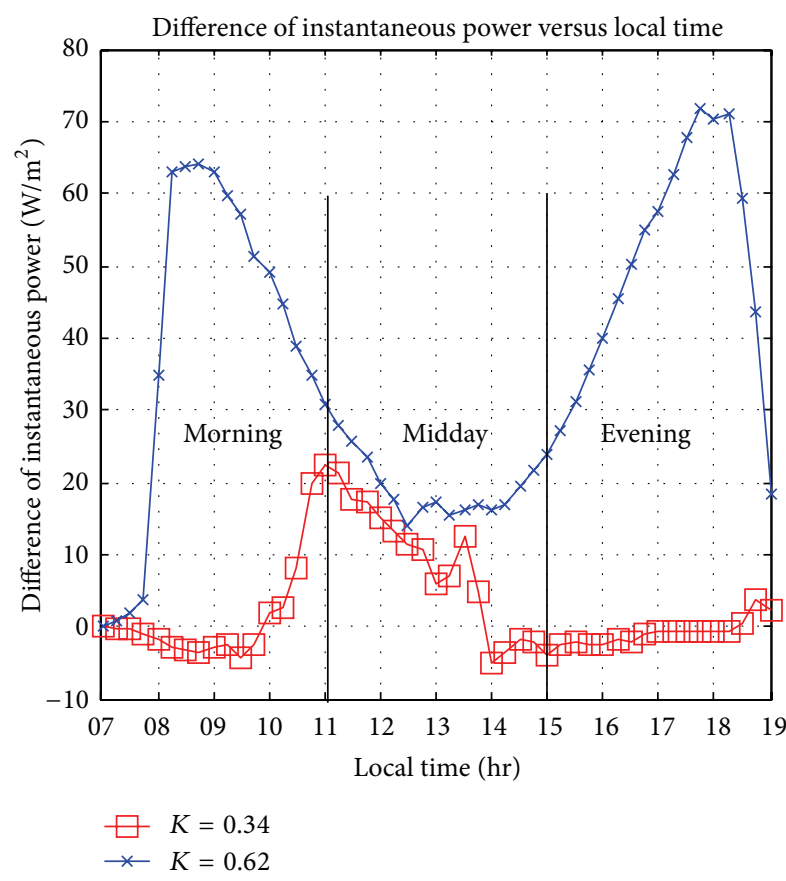

FIGURE 8: Difference of instantaneous power of DAST and SSS along the sunny day and cloudy day.

calculation of the energy gain. The voltage of the tracking system $V_{\text {track }}$ and the current drawn $I_{\text {drawn }}$ during the tracking process are shown in Figure 10.

The DAST tracking is done within fifteen seconds duration for consecutive fifteen minutes. The tracking time is short as the sun movement does not vary much in fifteen minutes. The DAST tracks the sun from $7 \mathrm{am}$ to $7 \mathrm{pm}$ which is equivalent to twelve hours. The approximate energy consumption used for tracking in a day can be calculated as follows:

$$
\begin{gathered}
E_{C}=\frac{13 \times 0.6 \times((15 / 60 \times 60) \times 12)}{1.58 * 0.812}, \\
E_{C}=0.30 \mathrm{Whr} / \mathrm{m}^{2} .
\end{gathered}
$$

The energy consumption $\left(E_{C}\right)$ is compared to the difference between the energy generated between DAST and Static Solar System (SSS) in a low and high clearness index day, respectively. Apparently, the energy consumption is relatively small compared to the energy difference of DAST and SSS for the DAST proposed in both high clearness index (sunny) and low clearness index (cloudy) day as shown in Table 1. Hence, the energy consumption $\left(E_{C}\right)$ can be safely left out from the calculation of the energy gained by the DAST over SSS without significant impact on the final result. However, the impact of energy consumption $\left(E_{C}\right)$ should not be overlooked in a larger system as its value would loom large and become significant to the difference of energy between DAST and SSS.

4.2. Results of Energy Obtained by DAST and SSS. Figure 11 presented the daily energy captured by DAST and SSS for a

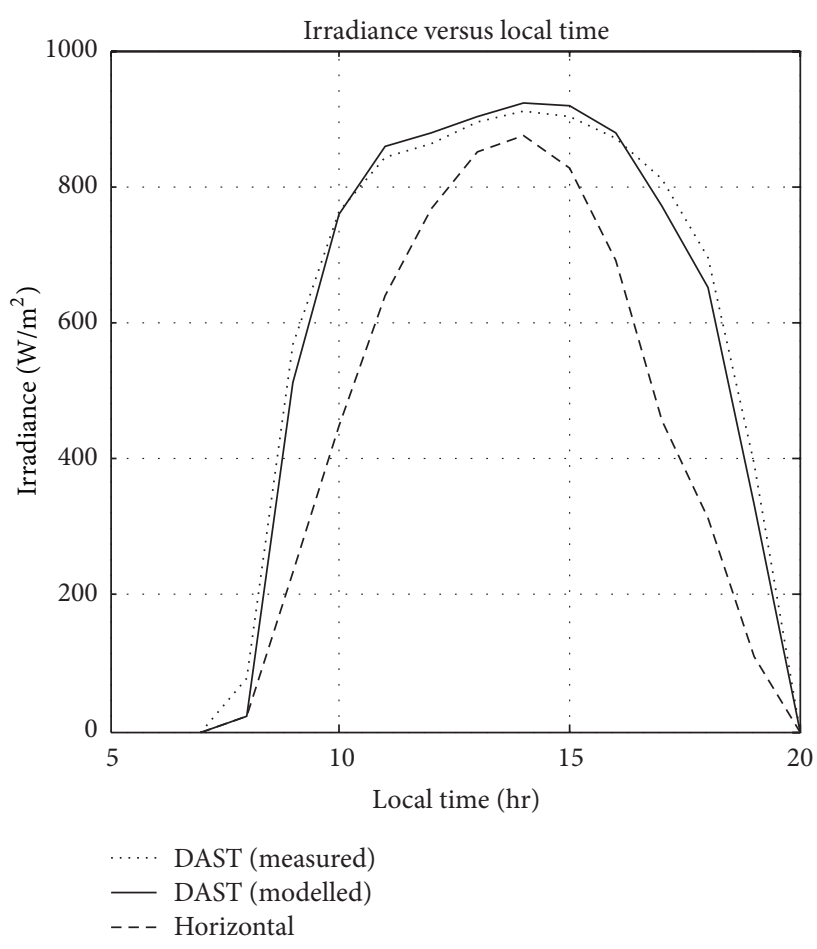

Figure 9: Measured and modeled (anisotropic diffuse model) instantaneous irradiance of DAST and measured irradiance of horizontally positioned SSS.

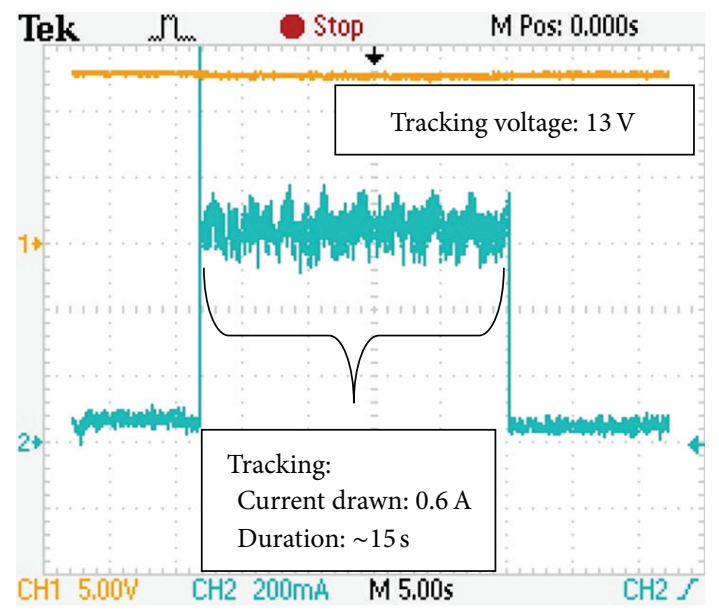

FIGURE 10: The voltage of the tracking system, $V_{\text {track }}$, and the current drawn, $I_{\text {drawn }}$, during the tracking process.

month in a bar chart. There are various conditions such as sunny days, cloudy days, and rainy days during this month which is the typical climate of Malaysia. The weather in a month could act as a miniature of the weather in a year.

Hence, the underlying factor that determines the amount of advantage of DAST over SSS has to be found out. As a result, it leads to the investigation of the energy gain of both DAST and SSS with respect to clearness index. The clearness index is imperative for the performance evaluation of a PV system. It indicates the clarity of a day and the 


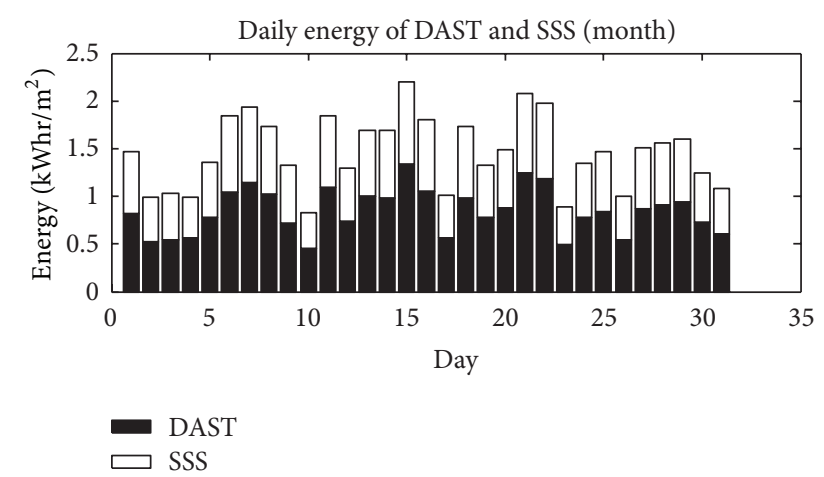

FIGURE 11: The daily energy captured by DAST and SSS for a month.

potential amount of sunlight for converting the solar energy into electrical energy by the PV system. The availability of abundant direct sunlight in a day has a profound impact on the energy generated by a PV system.

Generally, a direct proportional relationship could be hypothesized for both DAST and SSS with respect to clearness index. Based on the performance of both clear and overcast days reported on previous section, it could be deduced that DAST responds to clearness index on a more sensitive manner compared to a SSS. This is due to its ability to track the position of the sun and captured maximum sunlight from sunrise to sunset.

Figure 12 shows the energy captured by the DAST and SSS plotted against clearness index for a month. The trend lines for both systems are generated by using basic fitting in Matlab. The standard deviation of DAST and SSS is $0.0418 \mathrm{kWhr} / \mathrm{m}^{2}$ and $0.0175 \mathrm{kWhr} / \mathrm{m}^{2}$, respectively. The slope for both systems with respect to clearness index is apparently distinct from each other. Both trends of SSS and DAST have shown a linear growth with respect to clearness index. However, DAST has a steeper slope compared to SSS. On the other hand, at the days with low clearness index (below 0.22 ), presumably rainy days, DAST would have lower energy gain than SSS as shown in the extrapolation from the graph. It is due to the fact that the available solar radiation in those days is dominantly diffuse radiation. Direct radiation would be absent or at a relatively minimal level. Therefore, DAST has no advantage over SSS at this range of clearness index.

On the other side of the clearness index, the energy captured by DAST increases in a steeper slope compared to SSS as the clearness index climbs from medium (0.4) to high (0.6) level. Thus, it fortifies the inference that greater amount of energy will be captured by DAST compared to SSS as the clearness index increase. In other words, the application of DAST ensures a performance boost of a PV system and the outcome is exceptionally well as the clearness index increases. In addition, the trends of both DAST and SSS with respect to clearness index show that a clearness index offers a good estimation for energy generation on different weather.

4.3. Results of Daily Clearness Index. An endeavor to discover the relationship between clearness index and tracking advantage of DAST is made by plotting both efficiency and

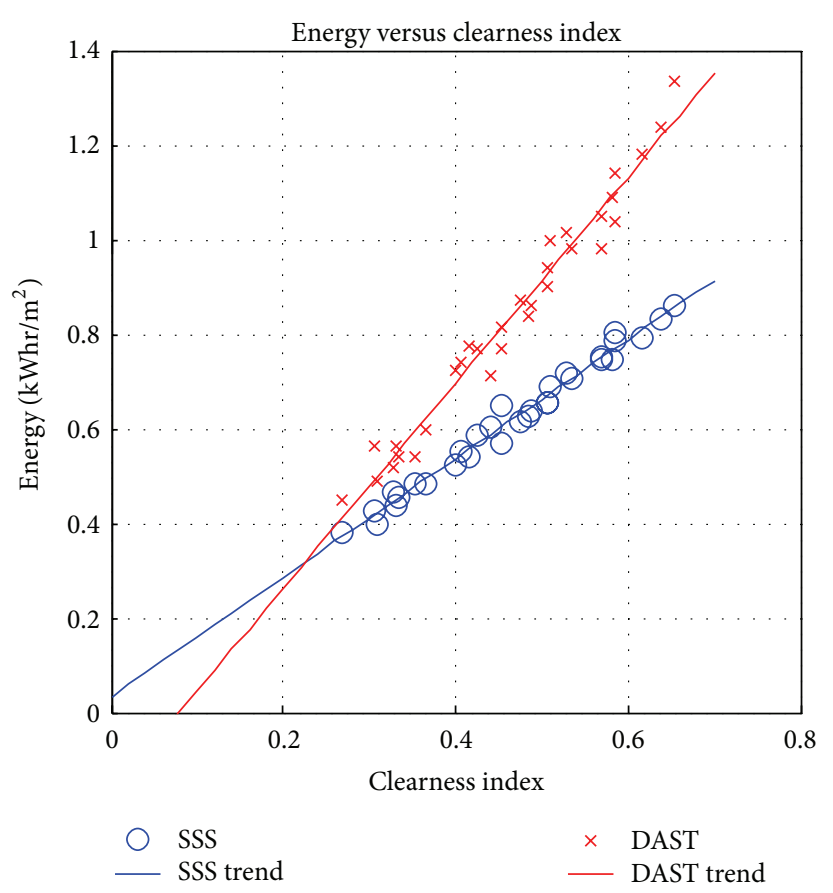

FIGURE 12: The energy captured by DAST and SSS against clearness index for a month.

additional electrical energy gained over the clearness index for one month duration. There are different kinds of weather within the period which includes sunny, overcast, partial cloudy, and rainy days. Figures 13 and 14 show the graphs of efficiency $(\eta)$ and Energy Gain $\left(E_{G}\right)$ versus daily Clearness Index $\left(K_{T}\right)$ by one month data of May 2013. A linear trend line is plotted via basic fitting for both graphs, respectively. Generally, these two graphs exhibit a weak trend of $\eta$ and $E_{G}$ proportional to $K_{T}$. The standard deviation of the efficiency and energy gain is $7.1757 \%$ and $0.0355 \mathrm{kWhr} / \mathrm{m}^{2}$.

The advantage of DAST over SSS is more remarkable at sunny day with high $K_{T}$ (between 0.5 and 0.6 ) compared to the overcast and rainy day with low $K_{T}$ (between 0.2 and 0.4 ). A clear and quantitative conclusion could not be drawn on the advantage of DAST based on the daily clearness index. It appears that there are some days that the efficiency and energy gain is scattered far off from the linear trend lines. Hence, a look on the energy gain versus time on Figure 8 would give a more detailed insight on how the slope of the DAST tracking advantage changes in a day. It has been found that the effectiveness or energy gain of DAST is particularly well in the morning and evening as compared to during the midday. This explains the weak trend above as the daily clearness index lump the slopes of the DAST tracking advantage on morning, midday, and evening without considering that they have different value of slope.

4.4. Results of Segmented Clearness Index. It is necessary to divide the clearness index into three segments period which are morning (0700-1100), midday (1101-1500), and evening (1501-1900) for a better visualization of the influence of 


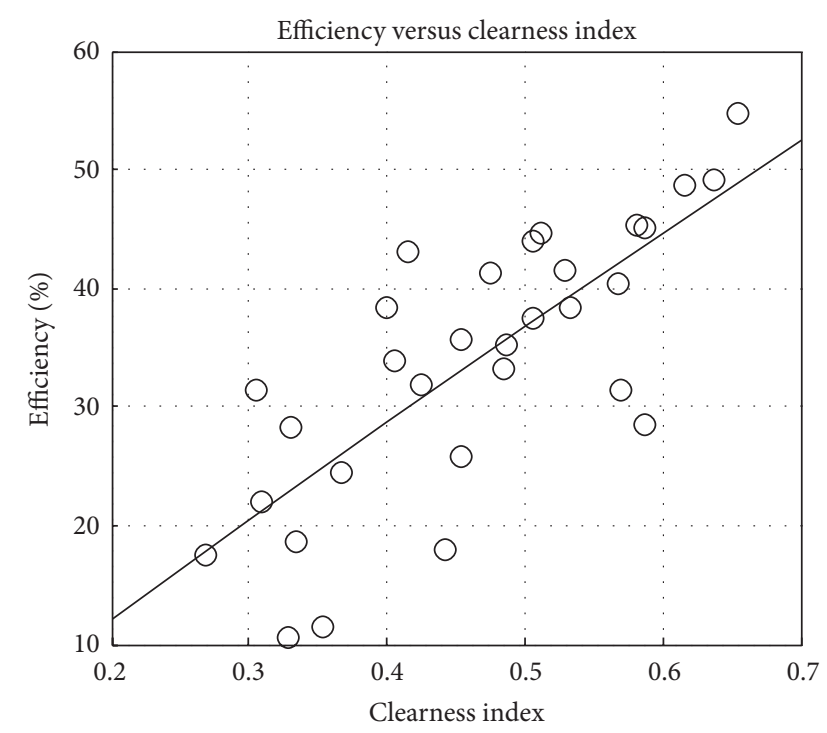

FIGURE 13: Efficiency of DAST over SSS versus daily clearness index.

clearness index. Nevertheless, the splitting of the day into three segments is not without a tradeoff. Since the clearness index is split into three periods, the efficiency of DAST over SSS for a single day could not be established as the portion contributed by efficiency for three periods and could not be summed into a total amount as energy gain. Thus, the total efficiency of a single day could not be obtained although the total energy gain of DAST can be summed from the three segments. The tradeoff is justified as a more accurate energy gain of DAST over SSS resulted from the segmented analysis. An accurate energy gain is extremely handy for estimating the additional profit generated by DAST as the Feed-In Tariff (FID) is based on the energy generated (kWhr) instead of efficiency. Figure 15 shows the energy gain of DAST over SSS versus clearness index on three segments period. The three trend lines are generated with polyfit and polyval functions in Matlab by fitting the experimental data points in least square sense. The trend lines on morning, midday, and evening for energy gain versus clearness index are fitted in second-order polynomial based on the scattered data points. Apparently, the trend of energy gain with respect to clearness index is clearer as the day is being segmented into three periods. Again, the sharp slopes of the efficiency and energy gain of DAST over SSS during the morning and evening period are different compared to the smaller slope in midday. The slope of the energy gain is lower at midday because SSS is positioned on a horizontal orientation. During the midday, sun light strikes on the PV panel of SSS with a smaller incidence angle compared to morning and evening. Most of the solar energy is captured by SSS within this period. Thus, the energy gained by DAST over SSS increases in a smaller slope as clearness index increases. During morning and evening, DAST has the advantage of facing the solar disk while SSS stay on its static horizontal position. As a result, the energy gained by DAST is a lot greater as the day is clearer and

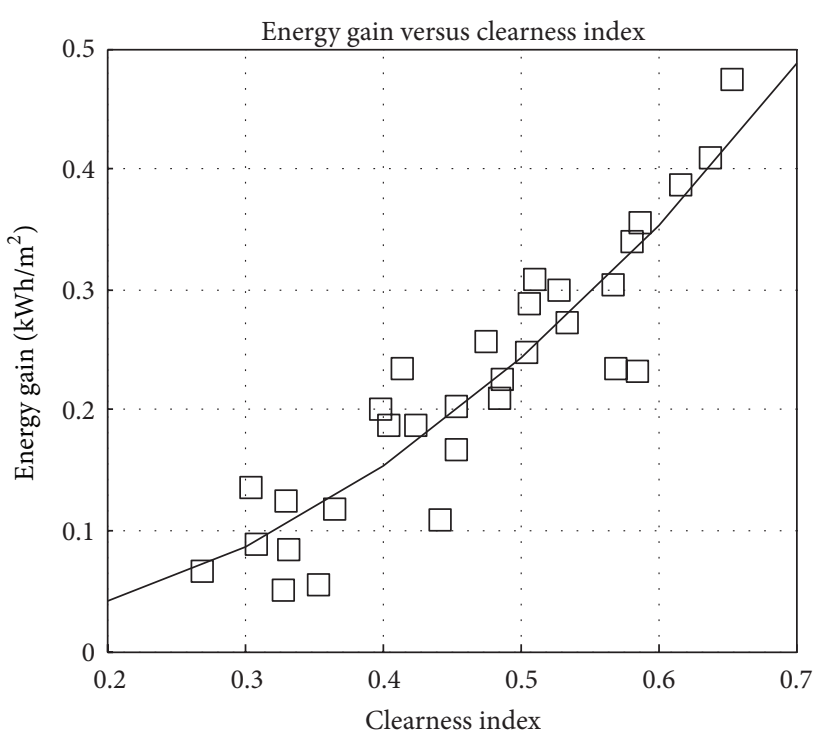

FIGURE 14: Energy gain of DAST over SSS versus daily clearness index.

more solar energy is available. However, the advantage diminishes as the clearness index drops. As clearness index drops below approximately 0.15 , the energy captured by DAST is less than SSS as there is only diffuse radiation available. A horizontally positioned SSS inclined position. Anyway, the energy captured on this level of clearness index is marginal. The standard deviation for the trend lines and data points are $0.0113 \mathrm{kWhr} / \mathrm{m}^{2}, 0.0133 \mathrm{kWhr} / \mathrm{m}^{2}$, and $0.0109 \mathrm{kWhr} / \mathrm{m}^{2}$ for morning, midday, and evening, respectively. It seems that the data points are distributed in a smaller range in the three segments clearness index compared to the daily clearness index shown in previous section. Hence, the energy gain of a DAST over SSS can be estimated in a better accuracy by using segmented clearness index graph given the clearness index of a site.

4.5. Comparison of Energy Gain of Seven Cities by Using Segmented Clearness Index and Anisotropic Model. The energy gain versus segmented clearness index graph is used to estimate the energy gain of other cities in Peninsular Malaysia based on the segmented clearness index of the cities, respectively. The performance improvement of DAST over SSS in seven cities of Peninsular Malaysia including Bayan Lepas, Ipoh, Kuantan, Muadzam Shah, Langkawi, Senai, and Subang are being estimated by the segmented clearness index graph method as shown in Figure 16. The hourly data of global irradiation over horizontal surface in 2009 for the seven cities is obtained from Malaysia Meteorological Department. These data were measured by using pyranometer in the weather stations at the seven cities, respectively. Segmented clearness index can be generated from these data and plotted on the segmented clearness index graphs to compute the energy gain of DAST over SSS. Moreover, these data are also put into HDKR anisotropic model to develop the global irradiation over the DAST [21]. Electrical energy generated by both 


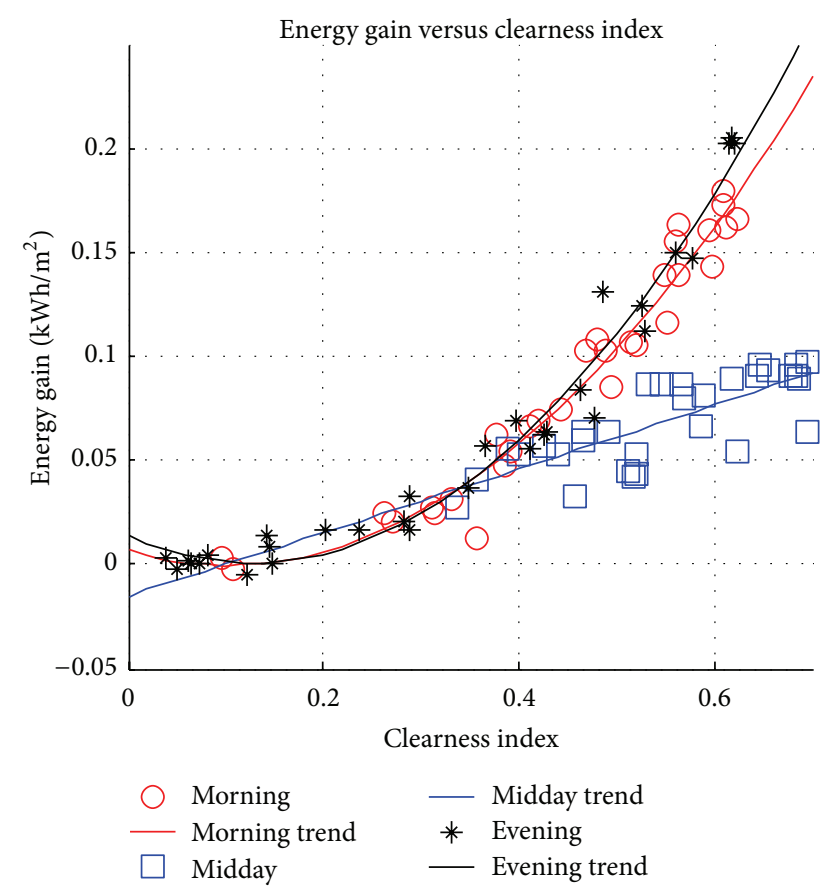

FIGURE 15: Energy gain of DAST over SSS on 3 segments period.

DAST and SSS can be converted from the global irradiation, respectively, by using the average effectiveness of the PV panel on DAST and SSS, 0.15 . The energy generated for both systems in a year are being averaged into a mean daily energy generated and divided into three segments. Subsequently, average energy gain of DAST over SSS on the three periods can be obtained by using the mean energy generated for both systems in three segments.

The average efficiency and energy gain of DAST over SSS in three segments of a day by using anisotropic model are plotted on the segmented clearness index graphs. It is observed that there are some similarities on the response of efficiency and energy gain of DAST over SSS with respect to the segmented clearness index in both anisotropic model and segmented clearness index curve from experimental. The slopes of both anisotropic model and experimental generally agree with each other albeit some discrepancies appearing due to some reasons. The value generated from anisotropic model tends to be slightly higher due to the horizon brightening component that may be estimated on a higher level than the actual level [22]. Besides that, an accurate estimation of the irradiation for anisotropic model cannot be obtained as there are a few days in a year that the weather stations in the seven cities were undergoing maintenance and data are not available during the short stint. Nonetheless, it has shown that the segmented experimental generated curve that can be used to estimate the energy gain of DAST over SSS with a low margin of error. The energy gain of DAST over SSS based on both anisotropic model and segmented experimental generated curve are tabulated on Tables 2, 3, and 4 for morning, midday, and evening. It has been shown that, in terms of energy gain of DAST

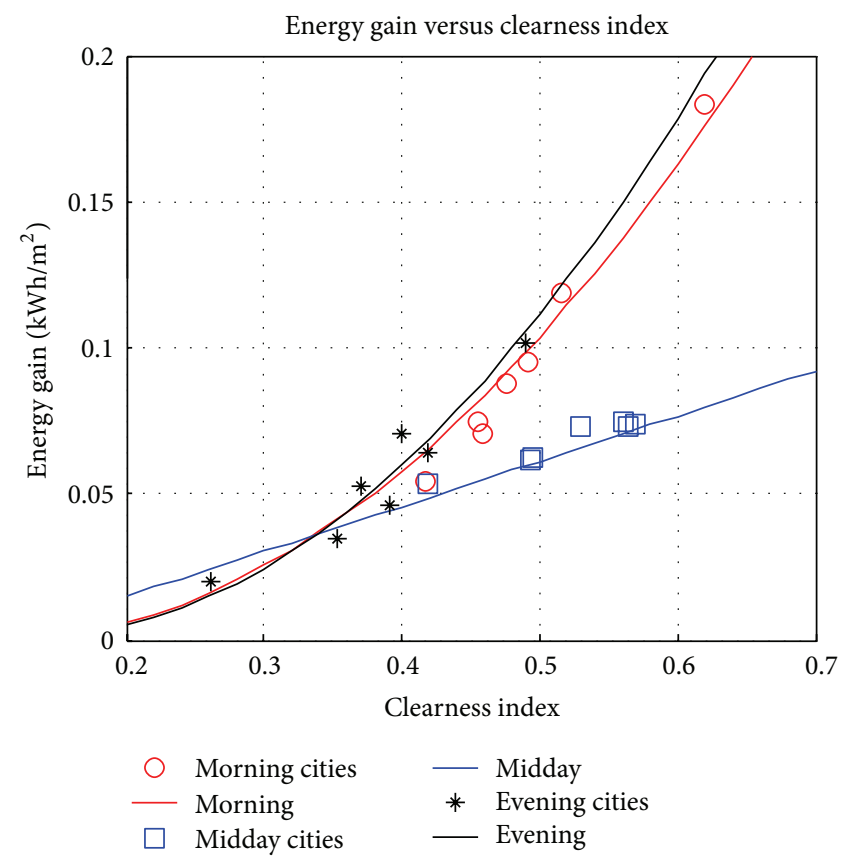

FIGURE 16: Energy gain of DAST over SSS for 7 cities developed by anisotropic model on 3 segments clearness index.

TABLE 2: Energy gain based on experimental curve and isotropic model on morning segment.

\begin{tabular}{lccc}
\hline \multirow{2}{*}{ Cities } & \multirow{2}{c}{$K_{T}$} & \multicolumn{2}{c}{ Energy gain $\left(\mathrm{kWhr} / \mathrm{m}^{2}\right)$} \\
& & Experiment & Anisotropic \\
\hline Bayan Lepas & 0.458 & 0.083 & 0.071 \\
Ipoh & 0.476 & 0.091 & 0.088 \\
Kuantan & 0.515 & 0.112 & 0.119 \\
Langkawi & 0.619 & 0.175 & 0.183 \\
Muadzam Shah & 0.455 & 0.081 & 0.074 \\
Senai & 0.417 & 0.064 & 0.055 \\
Subang & 0.492 & 0.099 & 0.095 \\
\hline
\end{tabular}

over SSS, Langkawi has the greatest potential for installing DAST while Senai has the least advantage among the seven cities. Langkawi is an island and is close to the coastal area, the clearness index is higher, and clearer days are available throughout the year. Senai is on the southern part of the Peninsular Malaysia and in an inland site which leads to higher precipitation and relatively regular rainfall. Hence, it has lower clearness index on three segments of the day and lower energy gain of using DAST.

Consider a proposed $1 \mathrm{MW}$ PV solar farm in Langkawi which is expected to produce $1310 \mathrm{MWhr}$ from horizontal orientation system per year from 4800 solar panels. The additional profit by incorporating DAST onto this solar farm is calculated. The Malaysia feed-in-tariffs (FIT) for grid-connected PV systems with $1 \mathrm{MW}$ capacity are up to $\$ 0.35 / \mathrm{kWhr}$ as of year 2013. The additional energy gain of DAST in Langkawi is $0.31 \mathrm{kWhr} / \mathrm{m}^{2}$. A $1 \mathrm{MW}$ PV system with $210 \mathrm{~W}$ and an area of $1.283 \mathrm{~m}^{2} \mathrm{PV}$ panels could generate 
TABLE 3: Energy gain based on experimental curve and isotropic model on midday segment.

\begin{tabular}{lccc}
\hline \multirow{2}{*}{ Cities } & $K_{T}$ & \multicolumn{2}{c}{ Energy gain $\left(\mathrm{kWhr} / \mathrm{m}^{2}\right)$} \\
& & Experiment & Anisotropic \\
\hline Bayan Lepas & 0.561 & 0.071 & 0.075 \\
Ipoh & 0.564 & 0.071 & 0.073 \\
Kuantan & 0.494 & 0.060 & 0.062 \\
Langkawi & 0.529 & 0.066 & 0.073 \\
Muadzam Shah & 0.495 & 0.060 & 0.062 \\
Senai & 0.418 & 0.049 & 0.053 \\
Subang & 0.570 & 0.072 & 0.074 \\
\hline
\end{tabular}

TABLE 4: Energy gain based on experimental curve and isotropic model on evening segment.

\begin{tabular}{lccc}
\hline \multirow{2}{*}{ Cities } & $K_{T}$ & \multicolumn{2}{c}{ Energy gain $\left(\mathrm{kWhr} / \mathrm{m}^{2}\right)$} \\
& & Experiment & Anisotropic \\
\hline Bayan Lepas & 0.490 & 0.105 & 0.101 \\
Ipoh & 0.370 & 0.048 & 0.052 \\
Kuantan & 0.391 & 0.056 & 0.046 \\
Langkawi & 0.420 & 0.069 & 0.064 \\
Muadzam Shah & 0.354 & 0.041 & 0.035 \\
Senai & 0.262 & 0.015 & 0.020 \\
Subang & 0.401 & 0.061 & 0.071 \\
\hline
\end{tabular}

TABLE 5: Technical characteristics of PV panel.

\begin{tabular}{lc}
\hline \multicolumn{2}{c}{ Sanyo HIP-210NKHB5 } \\
\hline Maximum power $\left(P_{\max }\right)[\mathrm{W}]$ & 210 \\
Max. power voltage $\left(V_{\mathrm{mp}}\right)[\mathrm{V}]$ & 41.3 \\
Max. power current $\left(I_{\mathrm{mp}}\right)[\mathrm{A}]$ & 5.09 \\
Open circuit voltage $\left(V_{\mathrm{oc}}\right)[\mathrm{V}]$ & 50.9 \\
Short circuit current $\left(I_{\mathrm{sc}}\right)[\mathrm{A}]$ & 5.57 \\
Dimension $(L * W * D)[\mathrm{m}]$ & $1.58 * 0.812 * 0.035$ \\
Weight $[\mathrm{kg}]$ & 15 \\
Cell efficiency $[\%]$ & 18.9 \\
Module efficiency $[\%]$ & 16.4 \\
\hline
\end{tabular}

an additional energy of $1909 \mathrm{kWhr}$ per day. Assume a 10\% inverter loss for converting the DC (Direct Current) power from PV into AC (Alternating Current) for feeding into grid, $\$ 601.34$ daily extra profit can be obtained by using DAST. An annual additional profit of $\$ 219,499$ is the advantage of DAST over SSS. Similar financial analyses on the other cities which are being done and the additional financial gain due to the advantage of DAST over SSS are shown in Figure 17. The estimated profit could offer important information for solar farm investor in making decision whether the longterm investment is sustainable after deducting the one-off additional cost of mechanical structure and motor for DAST. More detailed studies on the cost estimation of DAST and its variation with respect to capacity will be the goal for future work. In this analysis, the focus is put upon the average additional energy gain of DAST over SSS with respect to clearness index.

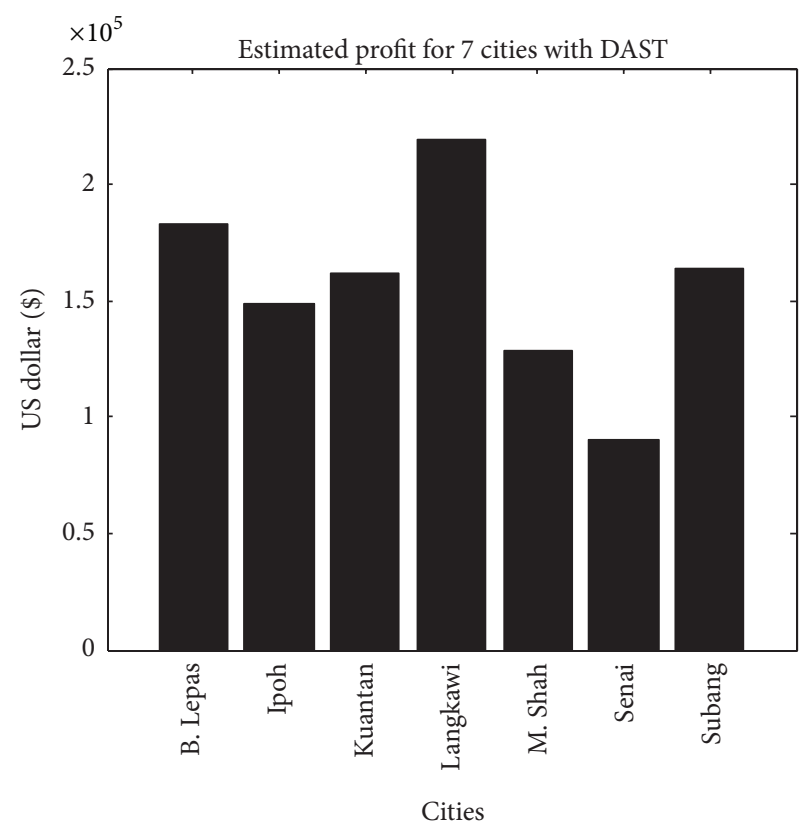

FIGURE 17: Estimated additional financial gain for seven cities with DAST.

\section{Conclusion}

This work demonstrates the correlation of clearness index with energy gain and efficiency of DAST over SSS based on experimental setup. Apparent advantage of DAST occurs in morning and evening sessions due to the ability of DAST to follow the sun's position throughout the day as compared to the static position of SSS. A segmented clearness index graph for the experimental result is plotted and it shows a lower standard deviation and better correlation for clearness index with both energy gain and efficiency during morning, midday, and evening. This correlation has been used, respectively, to estimate the energy gain of seven cities in Peninsular Malaysia and compared with their value developed by anisotropic model. A similar trend for the response of energy gain and efficiency to clearness index is found. It shows that this correlation can offer an estimation of the energy gain of DAST over SSS while considering the potential of installing PV system on a site. Additional financial gain due to the advantage of DAST over SSS for seven cities is also calculated based on a $1 \mathrm{MW}$ PV solar farm case study and Malaysia feed-in-tariffs (FIT). Moreover, this work could be a starting point for further detailed economic analysis for DAST. More economical details included cost analysis of DAST; ground field price and payback period could be explored to validate the investment model of DAST solar farm in the future works.

\section{Nomenclature}

DAST: Dual Axis Solar Tracker

SSS: Static Solar System

PV: Photovoltaic 
$K_{T}: \quad$ Clearness index for a day (-)

$k_{T}$ : Clearness index for an hour (-)

$G$ : $\quad$ Global solar radiation over a day $\left(\mathrm{W} / \mathrm{m}^{2}\right)$

$H_{o}$ : Extraterrestrial radiation over a day $\left(\mathrm{W} / \mathrm{m}^{2}\right)$

$I_{G}: \quad$ Global solar radiation over an hour $\left(\mathrm{W} / \mathrm{m}^{2}\right)$

$I_{o}$ : Extraterrestrial radiation over an hour $\left(\mathrm{W} / \mathrm{m}^{2}\right)$

$G_{\text {SC }}: \quad$ Solar constant, $1367\left(\mathrm{~W} / \mathrm{m}^{2}\right)$

$n: \quad$ Julian day (-)

$\phi: \quad$ Latitude $\left({ }^{\circ}\right)$

$\delta: \quad$ Declination $\left({ }^{\circ}\right)$

$\omega_{s}: \quad$ Sunset hour angle $\left(^{\circ}\right)$

$\omega_{1}$ : $\quad$ Hour angle for start of an hour $\left({ }^{\circ}\right)$

$\omega_{2}$ : Hour angle for end of an hour $\left({ }^{\circ}\right)$

$\triangle E: \quad$ Energy gain of DAST over SSS $\left(\mathrm{kWhr} / \mathrm{m}^{2}\right)$

$E_{\text {DAST }}$ : Energy generated by DAST $\left(\mathrm{kWhr} / \mathrm{m}^{2}\right)$

$E_{\mathrm{SSS}}$ : Energy generated by SSS $\left(\mathrm{kWhr} / \mathrm{m}^{2}\right)$

$E_{C}: \quad$ Energy consumed by DAST $\left(\mathrm{kWhr} / \mathrm{m}^{2}\right)$

$V_{\text {track }}$ : The voltage of the tracking system $(\mathrm{V})$

$I_{\text {drawn }}$ : The current drawn by the tracking system (A)

MPPT: Maximum Power Point Tracking (-)

CV: $\quad$ Constant Voltage method for MPPT (-)

$\eta: \quad$ Efficiency of DAST over SSS (-)

$I_{T}: \quad$ Radiation received by tilted surface $\left(\mathrm{W} / \mathrm{m}^{2}\right)$

$I_{B}$ : Beam component of irradiance over horizontal surface $\left(\mathrm{W} / \mathrm{m}^{2}\right)$

$R_{B}: \quad$ Geometric factor (-)

$A_{i}: \quad$ Anisotropy index (-)

$f$ : $\quad$ Modulating factor account for cloudiness (-)

$I_{D}$ : Diffusive component of irradiance over horizontal surface $\left(\mathrm{W} / \mathrm{m}^{2}\right)$

$\beta$ : $\quad$ Slope of tilted surface $\left({ }^{\circ}\right)$

$\rho: \quad$ Albedo (-)

$I_{G}: \quad$ Radiation received by horizontal surface $\left(\mathrm{W} / \mathrm{m}^{2}\right)$

$\theta$ : $\quad$ Angle of incidence of beam radiation on tilted surface $\left(^{\circ}\right)$

$\theta_{Z}: \quad$ Solar zenith angle $\left({ }^{\circ}\right)$

$\gamma: \quad$ Solar azimuth angle $\left({ }^{\circ}\right)$.

\section{Acknowledgments}

The authors thank the technical and financial assistance of UM Power Energy Dedicated Advanced Centre (UMPEDAC) and the High Impact Research Grant (H16001-00-D000032).

\section{References}

[1] T. M. Razykov, C. S. Ferekides, D. Morel, E. Stefanakos, H. S. Ullal, and H. M. Upadhyaya, "Solar photovoltaic electricity: current status and future prospects," Solar Energy, vol. 85, no. 8, pp. 1580-1608, 2011.

[2] K. V. K. Reddy and M. V. Kumar, "Modeling and a MPPT method for solar cells," Journal of Engineering and Applied Sciences, vol. 3, no. 1, pp. 128-133, 2008.
[3] H. Mousazadeh, A. Keyhani, A. Javadi, H. Mobli, K. Abrinia, and A. Sharifi, "A review of principle and sun-tracking methods for maximizing solar systems output," Renewable and Sustainable Energy Reviews, vol. 13, no. 8, pp. 1800-1818, 2009.

[4] G. K. Singh, "Solar power generation by PV, (photovoltaic) technology: a review," Energy, vol. 53, pp. 1-13, 2013.

[5] J. Rizk and Y. Chaiko, Solar Tracking System: More Efficient Use of Solar Panels, vol. 41, World Academy of Science, Engineering and Technology, 2008.

[6] A.-J. N. Khalifa and S. S. Al-Mutawalli, "Effect of two-axis sun tracking on the performance of compound parabolic concentrators," Energy Conversion and Management, vol. 39, no. 10, pp. 1073-1079, 1998.

[7] G. C. Bakos, "Design and construction of a two-axis sun tracking system for Parabolic Trough Collector (PTC) efficiency improvement," Renewable Energy, vol. 31, no. 15, pp. 2411-2421, 2006.

[8] S. Abdallah and S. Nijmeh, "Two axes sun tracking system with PLC control," Energy Conversion and Management, vol. 45, no. 11-12, pp. 1931-1939, 2004.

[9] C. Alexandru and M. Comsit, "The energy balance of the photovoltaic tracking systems using virtual prototyping platform," in Proceedings of the 5th International Conference on European (EEM '08), pp. 1-6, Electricity Market, May 2008.

[10] T. Tomson, "Discrete two-positional tracking of solar collectors," Renewable Energy, vol. 33, no. 3, pp. 400-405, 2008.

[11] B. Ai, H. Shen, Q. Ban, B. Ji, and X. Liao, "Calculation of the hourly and daily radiation incident on three step tracking planes," Energy Conversion and Management, vol. 44, no. 12, pp. 1999-2011, 2003.

[12] E. Lorenzo, M. Pérez, A. Ezpeleta, and J. Acedo, "Design of tracking photovoltaic systems with a single vertical axis," Progress in Photovoltaics, vol. 10, no. 8, pp. 533-543, 2002.

[13] P. Y. Vorobiev, J. Gonzalez-Hernandez, and Y. V. Vorobiev, "Optimization of the solar energy collection in tracking and non-tracking photovoltaic solar system," in Proceedings of the 1st International Conference on Electrical and Electronics Engineering (ICEEE '04), pp. 310-314, Acapulco, Mexico, 2004.

[14] N. H. Helwa, A. B. G. Bahgat, A. M. R. El Shafee, and E. T. El Shenawy, "Maximum collectable solar energy by different solar tracking systems," Energy Sources, vol. 22, no. 1, pp. 23-34, 2000.

[15] M. A. M. Shaltout, A. Ghettas, and M. Sabry, "V-trough concentrator on a photovoltaic full tracking system in a hot desert climate," Renewable Energy, vol. 6, no. 5-6, pp. 527-532, 1995.

[16] M. J. Clifford and D. Eastwood, "Design of a novel passive solar tracker," Solar Energy, vol. 77, no. 3, pp. 269-280, 2004.

[17] A. Al-Mohamad, "Efficiency improvements of photo-voltaic panels using a sun-tracking system," Applied Energy, vol. 79, no. 3, pp. 345-354, 2004.

[18] K. S. Karimov, M. A. Saqib, P. Akhter, M. M. Ahmed, J. A. Chattha, and S. A. Yousafzai, "A simple photo-voltaic tracking system," Solar Energy Materials and Solar Cells, vol. 87, no. 1-4, pp. 49-59, 2005.

[19] W. D. Lubitz, "Effect of manual tilt adjustments on incident irradiance on fixed and tracking solar panels," Applied Energy, vol. 88, no. 5, pp. 1710-1719, 2011.

[20] F. Cruz-Peragón, P. J. Casanova-Peláez, F. A. Díaz, R. LópezGarcía, and J. M. Palomar, "An approach to evaluate the energy advantage of two axes solar tracking systems in Spain," Applied Energy, vol. 88, no. 12, pp. 5131-5142, 2011. 
[21] D. T. Reindl, W. A. Beckman, and J. A. Duffie, "Evaluation of hourly tilted surface radiation models," Solar Energy, vol. 45, no. 1, pp. 9-17, 1990.

[22] J. A. Duffie and W. A. Beckman, Solar Engineering of Thermal Processes, John Wiley \& Sons, New York, NY, USA, 2004.

[23] B. Y. H. Liu and R. C. Jordan, "The long-term average performance of flat-plate solar-energy collectors: with design data for the U.S., its outlying possessions and Canada," Solar Energy, vol. 7, no. 2, pp. 53-74, 1963.

[24] R. Perez, R. Seals, P. Ineichen, R. Stewart, and D. Menicucci, "A new simplified version of the perez diffuse irradiance model for tilted surfaces," Solar Energy, vol. 39, no. 3, pp. 221-231, 1987.

[25] D. G. Erbs, S. A. Klein, and J. A. Duffie, "Estimation of the diffuse radiation fraction for hourly, daily and monthly-average global radiation," Solar Energy, vol. 28, no. 4, pp. 293-302, 1982.

[26] C. Alexandru, "A novel open-loop tracking strategy for photovoltaic systems," The Scientific World Journal, vol. 2013, Article ID 205396, 12 pages, 2013.

[27] K. A. Aganah and A. W. Leedy, "A constant voltage maximum power point tracking method for solar powered systems," in Proceedings of the 43rd IEEE Southeastern Symposium on System Theory (SSST '11), pp. 125-130, Auburn, Ala, USA, March 2011.

[28] N. A. Kelly and T. L. Gibson, "Improved photovoltaic energy output for cloudy conditions with a solar tracking system," Solar Energy, vol. 83, no. 11, pp. 2092-2102, 2009.

[29] N. A. Kelly and T. L. Gibson, "Increasing the solar photovoltaic energy capture on sunny and cloudy days," Solar Energy, vol. 85, no. 1, pp. 111-125, 2011. 

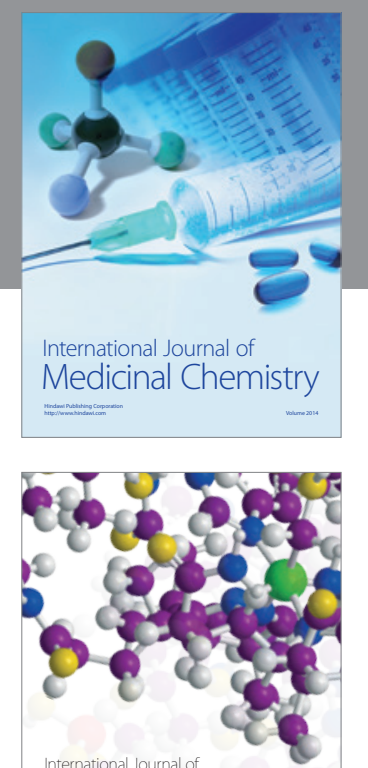

\section{Carbohydrate} Chemistry

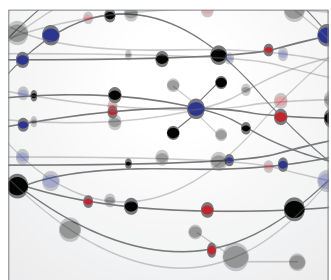

The Scientific World Journal
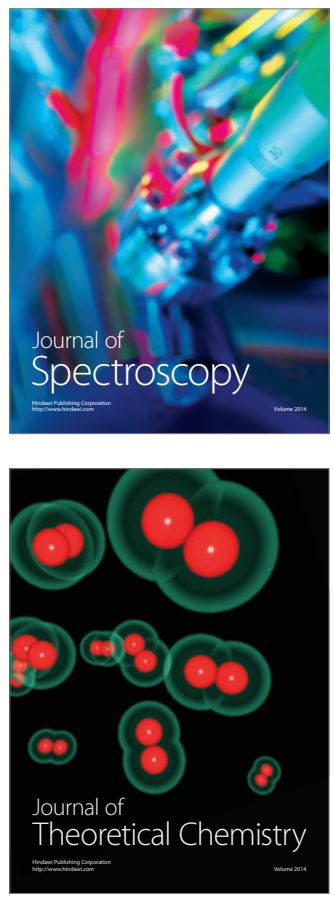
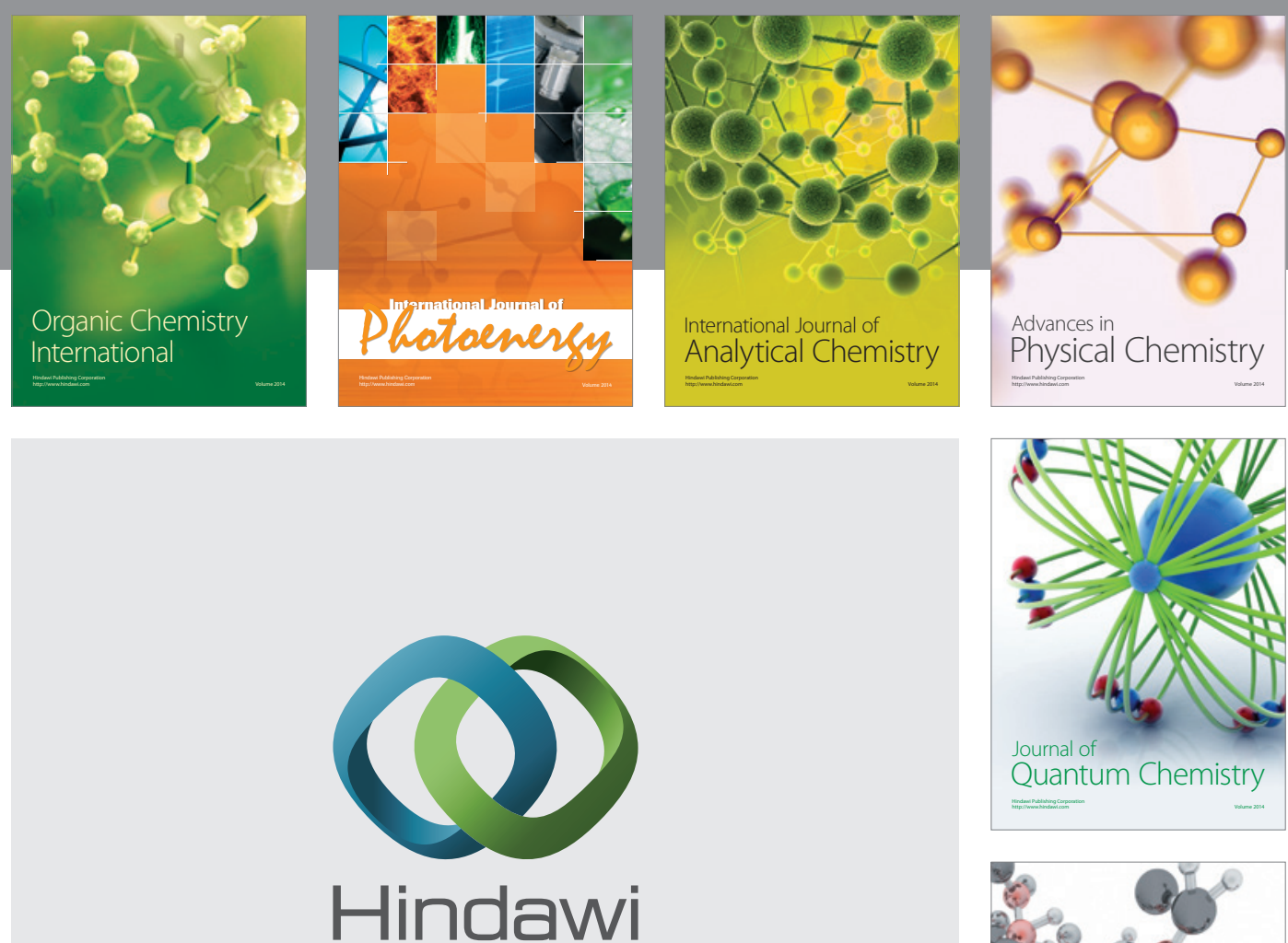

Submit your manuscripts at

http://www.hindawi.com

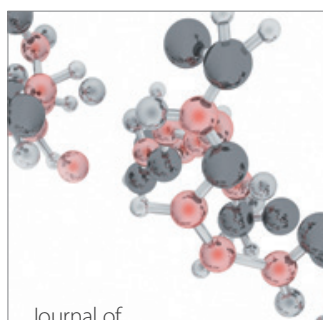

Analytical Methods

in Chemistry

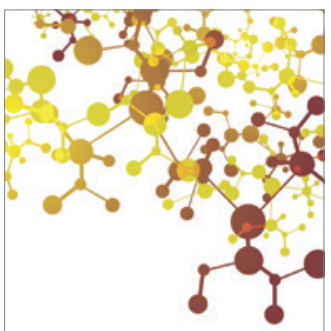

Journal of

Applied Chemistry

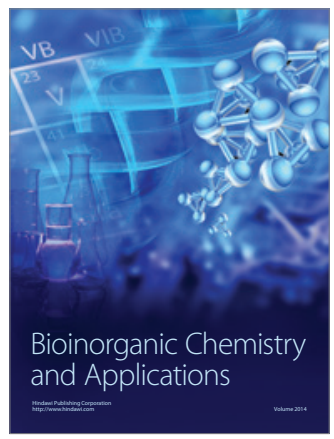

Inorganic Chemistry
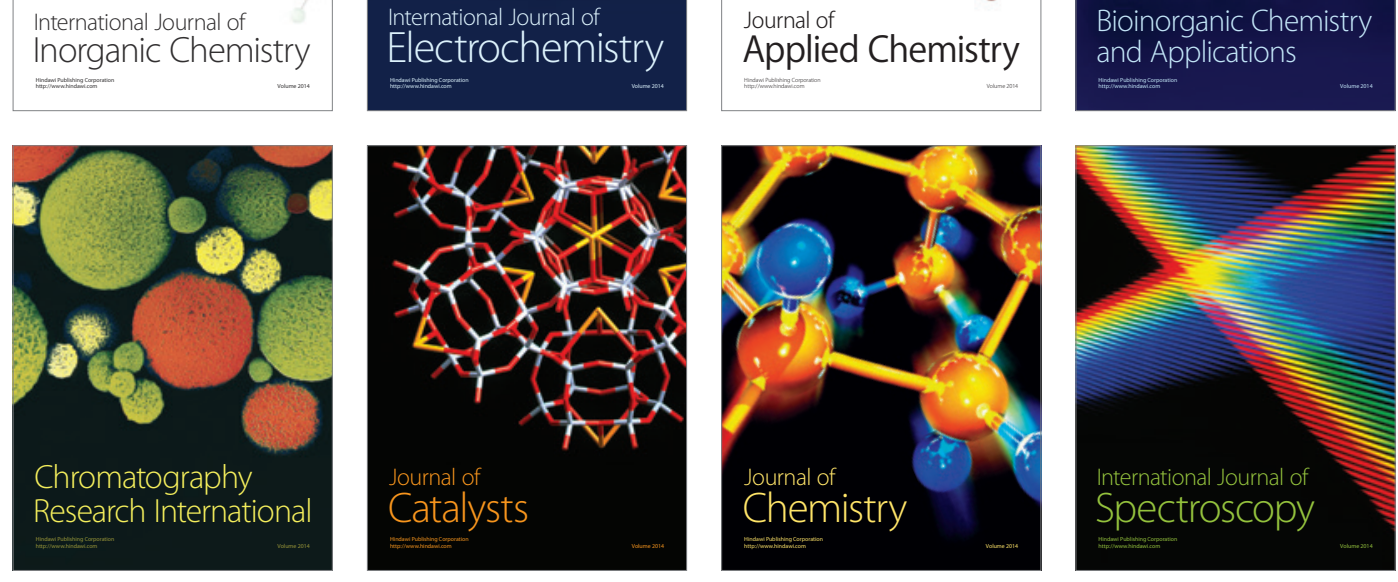